Child \& Adolescent Health

Elsevier Editorial System(tm) for The Lancet

Manuscript Draft

Manuscript Number: THELANCETCHILDADOL-D-18-00142R1

Title: Neonatal hyperbilirubinaemia

Article Type: Review (Invited)

Keywords: Neonates, neonatal jaundice, global burden, child health

Corresponding Author: Dr. Bolajoko O. Olusanya, MBBS, FMCPaed, FRCPCH, $\mathrm{PhD}$

Corresponding Author's Institution: Centre for Healthy Start Initiative

First Author: Bolajoko O. Olusanya, MBBS, FMCPaed, FRCPCH, PhD

Order of Authors: Bolajoko O. Olusanya, MBBS, FMCPaed, FRCPCH, PhD;

Michael Kaplan, MB ChB; Thor W Hansen, MD, PhD

Manuscript Region of Origin: NIGERIA

Abstract: Hyperbilirubinaemia, presenting as jaundice, is a ubiquitous and frequently benign transitional phenomenon in newborns. Yet it is a leading cause of hospitalisation in the first week of life. In some infants, jaundice may become severe, progressing to acute bilirubin encephalopathy and kernicterus with a significant risk of neonatal mortality and long-term neurodevelopmental impairments. Severe hyperbilirubinaemia and its sequelae continue to be encountered in industrialised countries with functioning medical systems while a disproportionately high burden also persists in low- and middle-income countries due primarily to delays in delivering known and effective treatment that are routinely available in high-income countries. In this Review, we summarise up-to-date evidence on the epidemiology of neonatal jaundice including its global burden based on estimates of the prevalence, fatal and non-fatal health outcomes. We also discuss the pathophysiology and management of severe hyperbilirubinaemia including the prevention of kernicterus, as well as highlight future directions for research. 


\section{Neonatal hyperbilirubinaemia}

Bolajoko O. Olusanya MD-PhD, ${ }^{\text {a a }}$ Michael Kaplan MB ChB, ${ }^{2}$ Thor W. R. Hansen MD-PhD ${ }^{3}$

${ }^{1}$ Executive Director, Centre for Healthy Start Initiative, 286A Corporation Drive, Dolphin Estate, Ikoyi, Lagos, NIGERIA Tel: +234 8033344300

Email: bolajoko.olusanya@uclmail.net

${ }^{2}$ Emeritus Director, Department of Neonatology, Shaare Zedek Medical Center, Jerusalem 91031; Faculty of Medicine of the Hebrew University, Jerusalem, Israel. Email: mkaplan@mail.huji.ac.il

${ }^{3}$ Emeritus Professor of Paediatrics, Neonatal Intensive Care, Division of Pediatrics and Adolescent Medicine, Oslo University Hospital and Institute for Clinical Medicine, Faculty of Medicine, University of Oslo, Norway. Email: t.w.r.hansen@medisin.uio.no

${ }^{\mathrm{a}}$ Corresponding author

Running title: Neonatal hyperbilirubinaemia 


\section{Summary}

Hyperbilirubinaemia, presenting as jaundice, is a ubiquitous and frequently benign transitional phenomenon in newborns. Yet it is a leading cause of hospitalisation in the first week of life. In some infants, jaundice may become severe, progressing to acute bilirubin encephalopathy and kernicterus with a significant risk of neonatal mortality and long-term neurodevelopmental impairments. Severe hyperbilirubinaemia and its sequelae continue to be encountered in industrialised countries with functioning medical systems while a disproportionately high burden also persists in low- and middle-income countries due primarily to delays in delivering known and effective treatment that are routinely available in high-income countries. In this Review, we summarise up-to-date evidence on the epidemiology of neonatal jaundice including its global burden based on estimates of the prevalence, fatal and non-fatal health outcomes. We also discuss the pathophysiology and management of severe hyperbilirubinaemia including the prevention of kernicterus, as well as highlight future directions for research.

\section{Search strategy and selection criteria}

Original and review articles in English language published in PubMed and Cochrane Library between January 1, 2005 and December 31, 2017 were retrieved using the search terms "neonatal jaundice", or "neonatal hyperbilirubinaemia" AND "epidemiology", "pathophysiology", "risk factors", "sequelae" or "management". We also considered commonly referenced and highly regarded papers published before 2005 . Relevant articles including book chapters from the reference lists of the publications identified by the search strategy were also reviewed. The start year of 2005 was chosen to capture relevant publications after the release of the landmark guidelines for neonatal hyperbilirubinaemia in 2004 by the American Academy of Pediatrics. 


\section{Introduction}

Unconjugated (indirect) hyperbilirubinaemia is a ubiquitous and frequently benign transitional phenomenon in newborns manifesting in the first days of life as jaundice (icterus neonatorum), a yellowish discolouration of the skin, sclera and mucous membranes. ${ }^{1,2}$ It is attributable to a metabolic imbalance favouring bilirubin production over hepatic-enteric bilirubin clearance. ${ }^{3,4}$ In some babies, excessive serum bilirubin concentrations may place them at risk of acute bilirubin encephalopathy (ABE) and kernicterus (chronic bilirubin encephalopathy) if not appropriately monitored and treated. ${ }^{5,6}$ Paradoxically, bilirubin is a valuable and potent antioxidant, and in vitro may provide this effect even at nanomolar concentrations through a cycle of oxidation-reduction between serum bilirubin and biliverdin. ${ }^{7}$ Serum bilirubin has also been established as the most potent superoxide with peroxyl radical scavenger activity. ${ }^{8}$ Yet, uncontrolled or rapidly rising hyperbilirubinaemia can reach neurotoxic levels with potentially lethal consequences. ${ }^{5,6}$ Thus, the welfare of jaundiced newborns is dependent on striking an appropriate balance between the protective effects and the risk of bilirubin neurotoxicity. The conjugated (direct) form of hyperbilirubinaemia, also commonly known as cholestatic jaundice, is usually pathologic and indicative of hepatic or biliary disease. ${ }^{9}$ It is rarely associated with bilirubin neurotoxicity and will therefore not be explored further in this paper.

The prevailing Sustainable Development Goals (SDGs) of the United Nations till 2030 which encompass a robust agenda for the survival, thriving and long-term wellbeing of all newborns ${ }^{10}$ have spurred a growing global interest in neonatal jaundice as a significant health condition. ${ }^{11,12}$ This Review therefore, seeks to provide up-to-date evidence on the epidemiology, pathophysiology, diagnosis and management of unconjugated hyperbilirubinaemia, including the prevention of kernicterus. It will also highlight future direction of the required efforts to curtail the disease burden, particularly in low- and middle-income countries (LMICs). 


\section{Epidemiology of neonatal hyperbilirubinaemia}

\section{Incidence}

For the identification of jaundice by visual inspection to be possible, total serum bilirubin (TSB) levels need to be $>5-6 \mathrm{mg} / \mathrm{dL}(85-100 \mu \mathrm{mol} / \mathrm{L})$, but even experienced neonatologists may misidentify infants with much higher levels. ${ }^{13}$ Jaundice thus identified affects at least $60 \%$ of fullterm and $80 \%$ of preterm newborns, ${ }^{14,15}$ suggesting that approximately $84-112$ million of the roughly 140 million babies born yearly worldwide ${ }^{16}$ will develop this condition in the first two weeks of life. About 1 in 10 newborns is likely to develop clinically significant jaundice or hyperbilirubinaemia requiring close monitoring and treatment. The precise TSB threshold of clinically significant jaundice is variable and influenced by postnatal age, race, co-morbid prematurity, sepsis, or haemolytic disorders. ${ }^{14,17}$ However, for practical purposes, the degree of jaundice in late-preterm and term infants can be classified roughly by TSB concentrations as significant, severe, extreme or hazardous as shown in the Panel. ${ }^{18,19}$ In a recent systematic review, the incidence of severe jaundice regardless of gestational age was reported as 37.8 (95\% CI: 6.9 205.4) cases per 10,000 live births. ${ }^{20}$ The highest incidence of 667.8 (95\% CI: 603.3 - 738.5) cases per 10,000 was reported in Africa and the lowest of 3.7 (95\% CI: $1.7-8.0)$ cases per 10,000 in Europe. A major observation in that review was the paucity of population-based data, especially from LMICs. Extensive hospital-based data have shown that severe jaundice is a leading cause of hospitalisation in the first week of life and accounts for up to $35 \%$ of hospital readmissions in the

first month of life. ${ }^{21-23}$ The incidence of chronic bilirubin encephalopathy or kernicterus ranges from approximately 0.2 to 2.7 cases per $100,000 .^{24,25}$

\section{Global disease burden}

To address the dearth of population-based data and the limitations of traditional systematic reviews in demonstrating that neonatal jaundice is an important cause of neonatal mortality and morbidity, it is common practice to use mathematical modelling tools to estimate fatal and non-fatal health 
outcomes of diseases for policy decisions. ${ }^{26,27}$ Bhutani and colleagues were perhaps the first to model the global burden of severe jaundice. ${ }^{28}$ They estimated that about $18 \%$ (or 1.1 million) of the annual live births of 134 million in 2010 developed clinically significant jaundice, 481,000 latepreterm and term neonates developed extreme hyperbilirubinaemia (TSB > $25 \mathrm{mg} / \mathrm{dL}$ ) in 2010, with 114,000 deaths and more than 63,000 survivors who suffered moderate or severe long-term neurological impairments. More recently, data from the Global Burden of Disease (GBD) Study in 2016 shows that neonatal jaundice accounted for 1,008 deaths per 100,000 live births (95\% Uncertainty interval or UI: $641.4-1,578.2$ ) and ranked 7th globally among all causes of neonatal deaths in the early-neonatal period $(0-6$ days $) .{ }^{12,29}$ The burden is highest in sub-Saharan Africa and South Asia where jaundice was the 8th and 7th leading cause of neonatal mortality respectively. It was the 11th leading cause in North America and 7th in Europe/Central Asia, within this period. In the late-neonatal period ( 7 - 27 days) it accounted for 167.8 deaths per 100,000 (95\% UI: 113.0 245.1) and ranked 10th globally. It ranked 11th in sub-Saharan Africa and 8th in South Asia, compared to 20th in North America and 14th in Europe/Central Asia. It was the $18^{\text {th }}$ leading cause of under-5 mortality from over 100 causes of child mortality globally.

Since survivors of severe jaundice are frequently at significant risk of long-term neurodevelopmental disabilities, $5,30,31$ it is useful to examine the burden of this condition using disability-adjusted life years (DALYs). DALYs are the sum of the years of life lost (YLLs) due to premature mortality and the years lived with disability (YLDs). ${ }^{32}$ This metric essentially combines mortality and morbidity outcomes for any condition. One DALY represents one year of healthy life lost because of the condition at the population level. Globally, neonatal jaundice accounted for 113,401 DALYs (95\% UI: 96,728 - 134,352) in 2016 and ranked 6th. It ranked 7th in all world regions except in Asia (ranked 6th), ahead of meningitis, tetanus and Zika virus. However, in the late neonatal period, it dropped to 8th position with 16,214 DALYs (95\% UI: 13,581 - 19,543) and was the $15^{\text {th }}$ leading cause of DALYs among children under-5 years globally. ${ }^{12}$ 
Barring the limitations commonly associated with statistical modelling of disease burden, ${ }^{27,29,32}$ perhaps the overarching evidence from the available data is that neonatal jaundice is an important cause of neonatal mortality and morbidity even though it is less prevalent than the more fatal entities like preterm birth, intrapartum complications including birth asphyxia, infections, and congenital anomalies.

\section{Risk factors}

A summary of the demographic, biological, laboratory and clinical risk factors for severe jaundice, inclusive of acute bilirubin encephalopathy and kernicterus, is presented in Table 1. The knowledge of these risk factors and their epidemiological profile in different racial populations is helpful for the early detection and effective management of infants with or at risk of severe jaundice. Probably the most prevalent of these factors are prematurity, haemolytic disease, perinatal infection and exclusive breastfeeding. ${ }^{2,14,33,34}$

Compared to full-term (37 or more weeks gestational age [GA]) infants, preterm ( $<37$ weeks GA) infants have a higher risk for severe jaundice with or without bilirubin-induced neurotoxicity primarily because of increased bilirubin production, hepatic immaturity in the uptake and conjugation of bilirubin, and increased enterohepatic circulation of bilirubin due to intestinal immaturity and delayed enteral feeding. ${ }^{35,36}$ Although this risk decreases with increasing gestational age due to increasing maturity, even late preterm (34 to 36 weeks GA) and early term (38 weeks GA) newborns have a higher risk of severe jaundice and neurotoxicity than full-term newborns. ${ }^{37}$ For example, of the 125 newborns reported in the voluntary US Kernicterus Registry, 30 (24\%) were 35 and 36 weeks GA. ${ }^{38}$ Of the 5 babies who died within the first postnatal week, 4 were less than 37 weeks GA. 
Haemolysis may present as a pathologic shortening of the life span of the red blood cells due to a wide range of genetic and non-genetic disorders such as isoimmune hemolytic disease (blood group incompatibility), glucose-6-phosphate-dehydrogenase (G6PD) deficiency, and hereditary spherocytosis. ${ }^{39}$ Exposure to certain oxidant substances such as sulfonamide products, methylene blue, naphthalene or fava beans eaten by nursing mothers triggers or exacerbates haemolysis in G6PD deficient newborns. Rh disease has been virtually eliminated in industrialised countries but is still a leading cause of haemolytic hyperbilirubinaemia globally. ${ }^{28,34,40}$ G6PD deficiency, once thought limited to the geographic regions to which it is indigenous, can now be encountered in virtually any corner of the globe, due to migration patterns and ease of travel. ${ }^{41}$

Sepsis predisposes to severe jaundice due to a combination of excess destruction of red cells and hepatocellular dysfunction, including intrahepatic biliary stasis. ${ }^{42}$ In one review, the contribution of infections to severe jaundice or kernicterus varied from $13.9 \%$ in Africa up to $31.2 \%$ in Asia, compared to $1.9 \%$ in Europe and North America. ${ }^{14}$ Pooled data from a more recent systematic review showed that infants diagnosed with sepsis in LMICs were independently at increased risk of severe hyperbilirubinaemia (OR, 9.15; 95\% CI, $2.78-30.1, \mathrm{p}<0.0001) .{ }^{34}$

Early initiation of breastfeeding within the first hour of life and exclusive breastfeeding in the first 6 months of life are widely promoted for newborns in both developed and developing countries through the Baby-Friendly Hospital Initiative. ${ }^{43,44}$ However, not all breastfed infants will receive optimal milk intake during the first few days of life. As a result, as many as 10-18\% of exclusively breastfed newborns in USA lose more than $10 \%$ of birth weight. ${ }^{44}$ Starvation or reduced caloric intake below the optimal intake for age in breastfed infants beyond age 5 days may result in increases in TSB concentrations due to increased intestinal re-absorption of unconjugated bilirubin. ${ }^{44}$ Breastfeeding jaundice should be distinguished from "breastmilk jaundice" commonly 
associated with prolonged unconjugated bilirubin, with typical onset after the fifth day of life and persisting beyond two weeks. ${ }^{44}$

Similarly, because delayed cord clamping in term infants for 30-60 seconds increases haemoglobin levels at birth and improves iron stores in the first several months of life, besides other benefits, the practice is widely recommended in many countries and supported by the World Health Organisation (WHO). ${ }^{45,46}$ However, it elevates the risk of jaundice for which proper monitoring is warranted, as a delay of 1 minute may raise the newborn haemoglobin level significantly and precipitate the need for phototherapy.

\section{Long-term sequelae}

Long-term neurodevelopmental disabilities frequently associated with severe jaundice with or without a diagnosis of bilirubin encephalopathy include choreo-athetoid cerebral palsy, ${ }^{47-49}$ auditory spectrum disorders, ${ }^{37,50-53}$ and general developmental delays. ${ }^{30,54}$ A growing number of studies are now exploring the risk of bilirubin-induced neurotoxicity in jaundiced infants based on unbound bilirubin rather than serum/plasma bilirubin. ${ }^{37,53}$ Few studies have associated severe jaundice with epilepsy, ${ }^{30,55}$ while the association with autism, ${ }^{56-59}$ and childhood asthma ${ }^{60-62}$ remains a subject of ongoing investigation and debate. In one rare longitudinal study in Finland, the authors investigated the long-term impact of severe hyperbilirubinaemia (TSB $\geq 20 \mathrm{mg} / \mathrm{dL}$ or $342 \mu \mathrm{mol} / \mathrm{L}$ ) on educational, occupational and social functioning in a cohort ( $\mathrm{n}=128$ versus 82 controls) over a 30 year period. $^{63}$ Besides other findings, $45 \%$ of the jaundiced infants experienced cognitive abnormalities in childhood well into adulthood. This was apparent in academic achievement ( $p$ $<0.0001)$ and the ability to complete secondary $(\mathrm{p}<0.0001)$ and tertiary $(\mathrm{p}<0.004)$ education. Childhood symptoms of hyperactivity/impulsivity $(\mathrm{p}<0.0001)$ and inattention $(\mathrm{p}<0.02)$ were more common in the jaundiced group, but in adulthood these symptoms were equally distributed between both groups. 
Taken together, the available evidence underscores the need for a long-term perspective for survivors of severe jaundice especially in LMICs where health, educational, social and vocational support services are generally lacking. This would require systematic interventions to address the three levels of delay in seeking, accessing and receiving timely and appropriate care in many LMICs. ${ }^{12,31}$ In developed countries, such delays, as well as system failure in healthcare delivery, are not uncommon post-discharge in infants born in hospitals, as well as in infants born at home or in small birthing units. ${ }^{38}$

\section{Pathophysiology of bilirubin metabolism}

Unconjugated hyperbilirubinaemia in the newborn infant occurs through two principal mechanisms:

i) Bilirubin production in the newborn is twice as high per kg body weight as it is later in life $(8.5 \mathrm{mg} / \mathrm{kg} /$ day vs $4.0 \mathrm{mg} / \mathrm{kg} /$ day $) .{ }^{64,65}$

ii) Induction of UGT1A1 which conjugates bilirubin in the liver is delayed, thus limiting excretion (Figure 1).

Increased production combined with limitations in excretion account for the accumulation of bilirubin in the immediate postnatal period. Neonatal hyperbilirubinaemia therefore reflects a transient imbalance in the interplay between developmentally modulated changes in bilirubin production and its excretion.

In the newborn, the lifespan of red blood cells is shorter than that of adults and varies from around 60 to 100 days. ${ }^{66}$ Bilirubin is produced from the degradation of haem (from senescent red blood cells, myoglobin from muscle, enzymes such as cytochromes and catalases) by haem oxygenase and biliverdin reductase within the reticuloendothelial system (Figure 1). This constitutes the first step in the metabolism of bilirubin. Biliverdin is an intermediate product with equimolar quantities of carbon monoxide and free iron released as by-products. Bilirubin is then transported to the liver in serum bound to albumin, but a small fraction is always unbound. The equilibrium concentration depends on several factors including the bilirubin/albumin molar ratio, the $\mathrm{pH}$, and the presence of 
competitors for the bilirubin binding site on albumin. Unbound bilirubin is lipid-soluble, and it is the bilirubin component capable of crossing the blood-brain barrier to occasionally cause life-long brain damage.

Following uptake into the hepatocytes, bilirubin is conjugated to water soluble forms, so called conjugated bilirubin, through glucuronidation by UDP-glucuronosyltransferase (UGT)1A1 (Figure 1). The immaturity and delay in the expression of UGT1A1 are major factors limiting bilirubin excretion. In the newborn period bilirubin in bile mainly appears as mono-conjugates, whereas later in life the di-conjugates constitute more than $80 \%$ of the total. ${ }^{67,68}$ In combination with the overproduction of bilirubin during this developmental stage, conjugated bilirubin once excreted may be deconjugated in the intestine and re-absorbed into the circulation by a process known as enterohepatic circulation, predisposing the infant to high TSB levels. This may contribute to increased and prolonged jaundice in the newborn infant and in extreme cases can add to the bilirubin pool leading to $\mathrm{ABE}$ or bilirubin-induced neurological dysfunction (BIND). ${ }^{6}$

Sequestration of blood from birth injuries (e.g. cephalohematoma) and congenital haemolytic conditions, the most common being G6PD deficiency, may also exacerbate hyperbilirubinaemia by increasing bilirubin production, further aggravating the imbalance in bilirubin metabolism. Furthermore, congenital disturbances in bilirubin metabolism with mutations in the UGT1A1 gene leading to life-long complete or partial loss of activity of the UGT1A1 enzyme, have been associated with pathological jaundice. The more severe Crigler-Najjar syndromes (types I and II) are associated with mutations in the gene coding areas which result in structurally altered UGT1A1 enzyme.

\section{Management of neonatal hyperbilirubinaemia}

The primary goal in the management of neonatal hyperbilirubinaemia is to avoid bilirubin-induced mortality and neurotoxicity in otherwise healthy newborns by preventing the serum bilirubin from 
reaching potentially neurotoxic concentrations. A summary of consensus-based clinical guidelines for the management of severe jaundice in late-preterm and term infants in industrialised and LMICs is available in the literature. ${ }^{19,69}$ The most widely cited is the 2004 Statement of the American Academy of Paediatrics (AAP), ${ }^{33}$ which has been adopted with minimal modifications by many national guidelines. Additional considerations have also been recommended for preterm newborns in view of the higher risk of bilirubin-induced neurotoxicity in this cohort, frequently at lower levels of TSB than anticipated (low bilirubin kernicterus), compared to late-preterm or term infants. ${ }^{14,70,71}$ An overview of key issues addressed in several guidelines, especially for high-burden LMICs is presented in Table 2.

\section{Primary prevention}

Jaundice is a naturally occurring phenomenon that cannot and probably should not be prevented in newborns. In the subset of infants at risk of severe jaundice it is important to ensure as far as practicable that this risk is promptly recognised and controlled. Educating mothers and healthcare practitioners on the difficulty in differentiating between jaundice which is normal and innocuous and that which carries a real danger for the baby is required. An awareness of the potential risks of severe jaundice with concomitant exposure to home-based haemolytic triggers like menthol and naphthalene substances in population groups with a high frequency of G6PD deficiency is also essential. ${ }^{72}$ Because bilirubin levels in infants with physiologic jaundice peak between the third and fifth day of life when most affected babies would have been discharged from hospital, mothers are usually the first to observe the onset of severe jaundice. Assessing the risk of severe jaundice in infants prior to discharge where infants are born in hospitals or other birthing units, is an important aspect of primary prevention. ${ }^{33}$ Risk factors include inter alia presence of jaundice in the first 24 hours of life, a positive history for neonatal jaundice in older siblings, a family history of haemolytic disease, evidence of haematomas or other sequestered blood, birth more than 2-3 weeks before term, as well as exaggerated postnatal weight loss and/or inadequate weight recovery. Empowering mothers to seek timely and appropriate referral is a critical first step in the prevention 
of potentially hazardous jaundice. ${ }^{73}$ Among mothers who deliver outside hospitals and lack the services of community health visitors after delivery this is even more pertinent. Simple-to-use and cost-effective tools to assist mothers to detect jaundice in their newborns in home-settings well before the early symptoms of $\mathrm{ABE}$ are currently under development in LMICs. ${ }^{74-76}$ Routine screening and monitoring for G6PD deficiency as well as Rh disease sensitisation should be emphasised especially in LMICs, more so as $\mathrm{Rh}$ disease has been successfully eliminated in developed countries.

\section{Early detection and diagnosis}

Prompt identification of jaundiced infants in and out of hospital should be incorporated routinely into the continuum of newborn care, which may be easily overlooked in settings with an overwhelming burden of more fatal neonatal illnesses. The cost-effectiveness of universal bilirubin screening remains a subject of debate because of the quality of the available evidence. For example, the AAP guidelines ${ }^{33}$ recommend universal pre-discharge bilirubin screening using TSB or transcutaneous bilirubin $(\mathrm{TcB})$ measurements to assess the risk of subsequent severe hyperbilirubinaemia. However, the US Preventive Services Task Force (USPSTF) submitted that available evidence was insufficient to make such a recommendation. ${ }^{77}$ This was corroborated by another evidence review in the UK. ${ }^{14}$ Notwithstanding, universal pre-discharge bilirubin screening is currently implemented in several settings in industrialised countries. More recent evidence suggests that while this program may be costly due to the high number of infants to be tested and treated, it was likely to be a better predictor of infants requiring treatment if the screening utilised

postnatal age-adjusted TSB/TcB combined with clinical risk factors, especially gestational age. ${ }^{15,78}$ The prospects in LMICs remain uncharted as detection of jaundiced infants largely relies on visual assessment by clinicians in many settings. 
Although TSB is a poor predictor of neurotoxicity compared to unbound bilirubin, ${ }^{79}$ it is still the diagnostic tool of choice and the measure for instituting and monitoring treatment efficacy, as tools for evaluating unbound bilirubin are not yet routinely available. ${ }^{80,81}$ The use of bilirubin/albumin (B/A) ratio as surrogate for plasma free bilirubin does not improve prediction of $\mathrm{ABE}$ or residual encephalopathy over TSB alone. ${ }^{82,83}$ The gold standard method for determining TSB in serum samples is high performance liquid chromatography (HPLC) as it is not subject to interference from haemoglobin or lipemia. ${ }^{84}$ However, this method is labour-intensive and not practical for routine use. In most clinical settings TSB is determined rather by the Diazo (Jendrassik-Gróf-based) reaction method or direct spectrophotometry. ${ }^{84,85}$

The use of TcB as proxy or pre-screening tool for TSB to reduce the rate of unnecessary and painful blood draws in newborns is not uncommon. ${ }^{14,25,33} \mathrm{TcB}$ devices are non-invasive and convert the colour of the baby's skin into a bilirubin value using specific algorithms. The devices are simple-touse and less costly than TSB bilirubinometers and the measurements highly correlate with TSB regardless of the gestational age. ${ }^{86}$ However, at the individual patient level, discrepancies between TcB and TSB measurements across racial populations could reveal clinically significant implications for decision-making. ${ }^{87,88}$ For example, approximately 1 in 3 black African neonates with hyperbilirubinaemia may be prone to TcB overestimation $(\geq 3 \mathrm{mg} / \mathrm{dL})$, resulting in unnecessary treatments where confirmatory TSB is not readily available. ${ }^{88}$ The reliability of TcB decreases rapidly at higher bilirubin levels (typically $>12 \mathrm{mg} / \mathrm{dl}$ or $205 \mu \mathrm{mol} / \mathrm{L}$ ), and most commercially available TcB devices cannot even measure bilirubin levels beyond approximately $20 \mathrm{mg} / \mathrm{dL}$ (340 $\mu \mathrm{mol} / \mathrm{L}) .{ }^{88,89} \mathrm{TcB}$ is also not a reliable proxy for an unbound bilirubin assay, ${ }^{90}$ while its use for evaluating the need for phototherapy or monitoring treatment efficacy remains controversial. ${ }^{91,92}$ Low-cost and minimally invasive point-of-care tools for plasma/serum bilirubin measurements, ${ }^{89,93}$ a smartphone application ("app") that uses digital images to estimate bilirubin levels" and a rapid 
G6PD screening technology that uses digital microfluidic fluorescence ${ }^{95}$ are currently under development and hold promise for LMICs.

\section{Treatment}

Phototherapy and exchange transfusion are mainstay treatments for severe hyperbilirubinaemia. Considerations for optimising these therapies are highlighted in Table 2. Phototherapy is always the first line of treatment, ${ }^{14,33}$ regardless of its side effects such as interference with mother-child bonding, imbalance of thermal environment and water loss. ${ }^{96}$ It is required even when exchange transfusion is indicated while awaiting preparation of the blood for transfusion. The goal of intervention is to lower the concentration of circulating bilirubin or keep it from increasing. In phototherapy photons, when interacting with the predominant bilirubin IX $\alpha(Z, Z)$ isomer, change the structure of bilirubin, converting it to isomers that are much more polar (photoisomers) and which therefore can be excreted in urine and bile without the need for conjugation. Essentially, the bilirubin products of phototherapy bypass the inadequate conjugation mechanisms in the newborn thereby accelerating elimination. ${ }^{96}$

An effective phototherapy device should produce specific blue-light wavelengths (peak emission: $450 \pm 20 \mathrm{~nm}$ ), preferably in a narrow bandwidth to as much of an infant's body surface area as possible. ${ }^{97}$ Conventional phototherapy should have an irradiance of at least $8-10 \mu \mathrm{W} / \mathrm{cm}^{2} / \mathrm{nm}$ and intensive phototherapy should have an irradiance of $\geq 30 \mu \mathrm{W} / \mathrm{cm}^{2} / \mathrm{nm}$ (from either a single or multiple phototherapy units). ${ }^{33}$ There are various phototherapy devices using different light sources: fluorescent tubes, halogen lamps and light emitting diodes (LED). In localities where special blue phototherapy lamps are not available or affordable, conventional white fluorescent lamps or green light can also achieve a good therapeutic outcome. ${ }^{14}$ LED devices are more power efficient, portable, weigh less, have a longer life span and lower heat production, making them more suitable

for intensive phototherapy than fluorescent bulbs. ${ }^{97,98}$ Regular monitoring of the irradiance from phototherapy devices is necessary to ensure that the irradiance remains within the therapeutic range. In remote tropical locations where access to conventional treatment is not assured heliotherapy, for 
example with specially filtered canopies, may be considered to minimise the risk of kernicterus. ${ }^{99}$ Evidence to support the use of clofibrate in combination with phototherapy ${ }^{100}$ and fluid supplementation for infants who require phototherapy are inconclusive. ${ }^{101}$

In recent years intravenous immune globulin (IVIG) has, in some settings, been shown to significantly reduce the need for exchange transfusion in infants with Rhesus or $\mathrm{ABO}$ incompatibility. ${ }^{25,101}$ Of note, Huizing et al used IVIG strictly as a rescue therapy for infants who had crossed, or were about to cross, the intervention limits for exchange transfusion. ${ }^{102}$ As most infants with blood group isoimmunisation can be managed very well with phototherapy only, using IVIG for all infants with blood group isoimmunisation will be wastefully expensive or even lead to a misconception about the utility of IVIG. ${ }^{25}$

Immediate exchange transfusion is warranted when phototherapy has failed to effectively reduce the rate of bilirubin rise and the $\mathrm{TSB} / \mathrm{TcB}$ measurement is near or exceeding exchange levels or if the infant has any of the signs of moderate to advanced ABE. This invasive procedure lowers the TSB concentration by removing circulating bilirubin. Secondary advantages include removal of antibody coated red blood cells in haemolytic disease (e.g. in rhesus and ABO sensitisation), or vulnerable red blood cells due to G6PD and other red cell enzyme deficiencies. ${ }^{103}$ Adverse events associated with ET, which can be fatal, include sepsis, electrolyte imbalance, air embolism, portal vein thrombosis, cardiac overload, thrombophlebitis, thrombocytopenia, necrotizing enterocolitis as well as the transmission of blood-borne diseases, even in settings with advanced clinical care. ${ }^{103}$ Ineffective phototherapy among severely jaundiced infants who present late in hospitals may elevate the risk of repeat exchange transfusions in poorly-resourced settings. ${ }^{104}$ Exchange transfusion with G6PD deficient donor blood should be avoided where possible as this may prolong time under phototherapy and result in repeat exchange transfusions. Similarly, blood should be 
screened for HIV and hepatitis. Rh-negative blood should be used for neonates with $\mathrm{Rh}$ isoimmunisation while $\mathrm{O}$ group should be used for neonates with $\mathrm{ABO}$ incompatibility.

The evidence in support of pharmacotherapies such as D-penicillamine, phenobarbital, bile salts, laxatives and bilirubin oxidase are inconclusive. ${ }^{105}$ Likewise, traditional herbs or medications used to treat newborn jaundice in many LMICs are generally not recommended in clinical settings because of the limited evidence on their safety and long-term effects. The therapeutic benefits of infant massage on neonatal hyperbilirubinaemia are still debated. Inadequate breastfeeding under the Baby-Friendly Hospital Initiative for exclusive breastfeeding continues to pose ethical dilemmas in poorly-resource settings with limited access to timely and effective treatment.

\section{Follow-up and neuro-developmental evaluation}

Clinically significant bilirubin rebound may occur, for example, in neonates with <37 weeks GA, positive direct Coombs test and those who received phototherapy before 72 hours. ${ }^{106}$ Such high-risk neonates should have a repeat bilirubin test about 24 hours after cessation of phototherapy, although they do not have to remain hospitalised for this purpose. ${ }^{33}$ Many cases of kernicterus reported from industrialised countries have occurred in infants who had been discharged as healthy from their birth hospitalisation. ${ }^{38}$ Several cases of "near miss" have had a similar history. ${ }^{107}$ It appears that a "crash-cart" approach to management of such infants has made avoidance of chronic sequelae possible in some cases. ${ }^{38,107}$ A system in which the responsibility for follow-up of jaundice in neonates during the first 2 weeks of life has clearly been placed with the birth hospital, appears to succeed in delivering an exceptionally low incidence of kernicterus (1:600 000). ${ }^{25}$ This suggests that the management of neonatal jaundice with a goal to avoid kernicterus, cannot be limited to the design of treatment charts and improvement in the quality control of phototherapy, but must encompass post-discharge follow-up as mandated in several national guidelines. Removing the road blocks for (re)admission and emergent management of infants who develop jaundice at home, are equally important. ${ }^{25,38,107,108}$ 
However, in most settings, clinicians still regard survival as the endpoint of successful treatment of acute neonatal illnesses. In some infants with $\mathrm{ABE}$ immediate reversal of the presenting symptoms after treatment may mask underlying long-term neurological and developmental sequelae that manifests subsequently in early childhood. The SDGs now mandate a child health framework that incorporates survival and thriving for the well-being of all children. ${ }^{11,109}$ Routine follow-up and evaluation of survivors of severe hyperbilirubinaemia for potential neurodevelopmental sequelae, including objective evaluation for possible auditory impairments, is therefore necessary to facilitate early detection and intervention for the affected infants. This must be considered as an integral part of any clinical protocol for the management of infants who have been treated for severe hyperbilirubinaemia. It is equally relevant for the emerging "nurturing care framework" for the disability-inclusive early childhood development programme under the auspices of WHO and UNICEF. ${ }^{110}$

\section{Future directions and conclusions}

In spite of this year marking the 60th anniversary of the discovery of phototherapy, ${ }^{111}$ and the fact that exchange transfusion had been practised for another decade before that, ${ }^{112}$ many aspects of neonatal jaundice remain an enigma. For example, the search for the putative basic mechanism of bilirubin neurotoxicity continues, 71 years after Richard Day published the first study in rats, which included both in vivo and in vitro experiments. ${ }^{113}$ The topic has been extensively reviewed by several researchers and all seem to have their favourite theory. ${ }^{4,6,36,114,115}$ Agreement on the basic mechanisms, assuming there is but one, would appear to be a sine qua non to plan further studies on how this (or those) mechanism(s) could be manipulated in order to reduce the vulnerability of the brain to bilirubin toxicity.

Among candidate mechanisms that have been proposed, and where pharmacologic or other interventions might be conceivable, are inflammation and the role of glial cells ${ }^{115}$ and blood-brain 
barrier transport molecules ("flippases"). ${ }^{114}$ Attention has also been focused on bilirubin photoisomers and their solubility characteristics relative to passage through the blood-brain barrier. ${ }^{4}$ Hypothetically the photoisomers of bilirubin because of their increased polarity should be less able to cross the blood-brain barrier, as polar molecules appear to need specific transporters to gain entry into the brain. While no such molecule capable of transporting bilirubin into brain has, at least as yet, been described, ABC transporters have been shown to reduce bilirubin brain entry. ${ }^{114}$ Despite multiple attempts by several groups, the perfect model to test the hypothesis of bilirubin photoisomers and brain entry has yet to be devised. ${ }^{4}$

Another avenue that needs to be pursued pertains to our ability to predict the development of severe neonatal jaundice. In industrialised countries kernicterus is rare and as such other aspects of bilirubin disease, including rate of readmission for hyperbilirubinemia or TSB concentrations exceeding predetermined levels, are used in lieu of kernicterus. Therefore, studies in countries where kernicterus continues to have a significant presence seem like a better arena in which to pursue such studies. Multiple enzymes and pathways are involved in bilirubin metabolism. Therefore, in addition to delineating clinical risk parameters, an intriguing proposal was recently advanced to use the principles of "pathway genetic load" to improve our prediction abilities. ${ }^{116}$

Furthermore, recognising that the road towards fulfilment of the above goals will take time, we need to work on acute management of infants with extreme hyperbilirubinaemia and signs of ABE. There is evidence that ABE may be reversible, at least in some cases, if handled with a "crash-cart" approach. ${ }^{105}$ Therefore, admission procedures for such infants must be streamlined in order to reduce the time lag between identification and start of treatment. Diagnostic approaches include the newly available end tidal carbon monoxide determination using a non-invasive, bedside device to determine the presence of haemolysis associated with a higher risk of severe hyperbilirubinaemia and neurotoxicity. A therapeutic modality which will hopefully become available in the very near 
future is that of metalloporphyrin, a drug capable of blocking haem oxygenase thereby preventing bilirubin production.

In conclusion, neonatal hyperbilirubinaemia is associated with significant fatal and non-fatal health outcomes globally with potentially devasting long-term consequences in some survivors. Community-oriented interventions to curtail the incidence of haemolytic jaundice, ensure timely access to effective treatment and provide appropriate follow-up for all newborns with or at risk of severe hyperbilirubinaemia, must be regarded as global health imperatives. This will ensure the health and well-being of the many beneficiaries of the substantial global investments towards reducing child mortality, especially in LMICs as recommended in the SDGs agenda.

\section{Funding}

No funding was received for this work by any of the authors.

\section{Contributors}

BOO drafted the manuscript. MK and TWRH critically reviewed and revised the manuscript for intellectual content. All authors approved the final version for submission.

\section{Declaration of interests}

The authors declared no conflicts of interest.

\section{Acknowledgement}

We thank the research team at the Centre for Healthy Start Initiative for assisting in retrieving and organising relevant articles used in this review.

\section{References}

1. Holt LE. The diseases of infancy and childhood: for the use of students and practitioners of medicine. New York: D. Appleton, 1897.

2. Dennery PA, Seidman DS, Stevenson DK. Neonatal hyperbilirubinemia. N Engl J Med 2001; 344: 581-90. 
3. Kaplan M, Muraca M, Hammerman C, et al. Imbalance between production and conjugation of bilirubin: a fundamental concept in the mechanism of neonatal jaundice. Pediatrics 2002; 110: e47.

4. Hansen TWR. Pathophysiology of kernicterus. In: Polin RA, Abman SH, Rowitch DH, Benitz WE, Fox WW (eds.) Fetal and neonatal physiology, 5th ed. Philadelphia, Elsevier. 2016, pp.1657-67.

5. Le Pichon JB, Riordan SM, Watchko J, Shapiro SM. The Neurological Sequelae of Neonatal Hyperbilirubinemia: Definitions, Diagnosis and Treatment of the Kernicterus Spectrum Disorders (KSDs). Curr Pediatr Rev 2017; 13: 199-209.

6. Watchko JF, Tiribelli C. Bilirubin-induced neurologic damage-mechanism and management approaches. N Engl J Med 2013; 369: 2021-30.

7. Doré S, Takahashi M, Ferris CD, et al. Bilirubin, formed by activation of heme oxygenase-2, protects neurons against oxidative stress injury. Proc Natl Acad Sci USA 1999; 96: 2445-50.

8. Farrera JA, Jaumà A, Ribó JM, et al. The antioxidant role of bile pigments evaluated by chemical tests. Bioorg Med Chem 1994; 2: 181-5.

9. Lane E, Murray KF. Neonatal Cholestasis. Pediatr Clin North Am 2017; 64: 621-39.

10. United Nations. Sustainable Development Goals. UN, New York, 2015. [http://www.un.org/sustainabledevelopment/sustainable-development-goals/. Accessed 25 March 2018].

11. Lawn JE, Blencowe H, Oza S, et al. Every Newborn: progress, priorities, and potential beyond survival. Lancet 2014; 384: 189-205.

12. Olusanya BO, Teeple S, Kassebaum NJ. The Contribution of Neonatal Jaundice to Global Child Mortality: Findings from the GBD 2016 Study. Pediatrics 2018;141: e20171471.

13. Riskin A, Abend-Weinger M, Bader D. How accurate are neonatologists in identifying clinical jaundice in newborns? Clin Pediatr (Phila) 2003; 42: 153-8.

14. National Institute for Health and Clinical Excellence (NICE). Neonatal jaundice: clinical guideline 98. May 2010 (http://www.nice.org.uk/ CG98). Accessed 25 March 2018.

15. Bhutani VK, Stark AR, Lazzeroni LC, et al. Predischarge screening for severe neonatal hyperbilirubinemia identifies infants who need phototherapy. J Pediatr 2013; 162: 477-82.

16. United Nations Children's Fund (UNICEF). The state of the world's children 2017. Children in a digital world. New York, 2017.

17. Ip S, Chung M, Kulig J, et al. An evidence-based review of important issues concerning neonatal hyperbilirubinemia. Pediatrics 2004; 114: e130-53.

18. Bhutani VK, Vilms RJ, Hamerman-Johnson L. Universal bilirubin screening for severe neonatal hyperbilirubinemia. J Perinatol 2010; 30 Suppl: S6-15. 
19. Olusanya BO, Ogunlesi TA, Kumar P, et al. Management of late-preterm and term infants with hyperbilirubinaemia in resource-constrained settings. BMC Pediatr 2015; 15: 39.

20. Slusher TM, Zamora TG, Appiah D, et al. Burden of severe neonatal jaundice: a systematic review and meta-analysis. BMJ Paediatrics Open 2017; 1: e000105.

21. The Young Infants Clinical Signs Study Group. Clinical signs that predict severe illness in children under age 2 months: a multicentre study. Lancet 2008; 371: 135-42.

22. Lain SJ, Roberts CL, Bowen JR, Nassar N. Early discharge of infants and risk of readmission for jaundice. Pediatrics 2015; 135: 314-21.

23. Battersby C, Michaelides S, Upton M, et al. Term admissions to neonatal units in England: a role for transitional care? A retrospective cohort study. BMJ Open 2017; 7: e016050.

24. McGillivray A, Evans N. Severe neonatal jaundice: is it a rare event in Australia? J Paediatr Child Health 2012; 48: 801-7.

25. Mreihil K, Benth JŠ, Stensvold HJ, Nakstad B, Hansen TWR; Norwegian NICU Phototherapy Study Group; Norwegian Neonatal Network. Phototherapy is commonly used for neonatal jaundice, but greater control is needed to avoid toxicity in the most vulnerable infants. Acta Paediatr 2018; 107: 611-9.

26. Young TK. Population health: concepts and methods. 2nd ed. New York, N.Y.: Oxford University Press; 2005.

27. Agyepong I, Corrah T, Guo Y, et al. Making sense of health estimates. Lancet 2015; 385: 13779.

28. Bhutani VK, Zipursky A, Blencowe H, et al. Neonatal hyperbilirubinemia and Rhesus disease of the newborn: incidence and impairment estimates for 2010 at regional and global levels. Pediatr Res 2013; 74 Suppl 1: 86-100.

29. GBD 2016 Causes of Death Collaborators. Global, regional, and national age-sex specific mortality for 264 causes of death, 1980-2016: a systematic analysis for the Global Burden of Disease Study 2016. Lancet 2017; 390: 1151-210.

30. Mwaniki MK, Atieno M, Lawn JE, Newton CR. Long-term neurodevelopmental outcomes after intrauterine and neonatal insults: a systematic review. Lancet 2012; 379: 445-52.

31. Olusanya BO, Ogunlesi TA, Slusher TM. Why is kernicterus still a major cause of death and disability in low-income and middle-income countries? Arch Dis Child 2014; 99: 1117-21.

32. GBD 2016 DALYs and HALE Collaborators. Global, regional, and national disability-adjusted life-years (DALYs) for 333 diseases and injuries and healthy life expectancy (HALE) for 195 countries and territories, 1990-2016: a systematic analysis for the Global Burden of Disease Study 2016. Lancet 2017; 390: 1260-344. 
33. American Academy of Pediatrics (AAP): Management of hyperbilirubinaemia in the newborn infant 35 or more weeks of gestation. Pediatrics 2004; 114: 297-316.

34. Olusanya BO, Osibanjo FB, Slusher TM. Risk factors for severe neonatal hyperbilirubinemia in low and middle-income countries: a systematic review and meta-analysis. PLoS One 2015; 10 : $\mathrm{e} 0117229$.

35. Raju TN. Developmental physiology of late and moderate prematurity. Semin Fetal Neonatal Med 2012; 17: 126-31.

36. Watchko JF. Bilirubin-Induced Neurotoxicity in the Preterm Neonate. Clin Perinatol 2016; 43: 297-311.

37. Amin SB, Wang H, Laroia N, Orlando M. Unbound Bilirubin and Auditory Neuropathy Spectrum Disorder in Late Preterm and Term Infants with Severe Jaundice. J Pediatr 2016; 173: 84-9.

38. Johnson L, Bhutani VK, Karp K, et al. Clinical report from the pilot USA kernicterus registry (1992 to 2004). J Perinatol 2009; 29(Suppl 1): S25-45.

39. Kaplan M, Hammerman C. Hemolytic disorders and their management. In: Stevenson DK, Maisels MJ, Watchko JF, editors. Care of the Jaundiced Neonate. New York: McGraw-Hill; 2012: 145-173.

40. Gamaleldin R, Iskander I, Seoud I, et al. Risk factors for neurotoxicity in newborns with severe neonatal hyperbilirubinemia. Pediatrics 2011; 128: e925-31.

41. Nkhoma ET, Poole C, Vannappagari V, Hall SA, Beutler E. The global prevalence of glucose6-phosphate dehydrogenase deficiency: a systematic review and meta-analysis. Blood Cells Mol Dis 2009; 42: 267-78.

42. Griffiths PD, Huntsman RG, Thomas CG. Neonatal Jaundice from Sepsis. Br Med J 1964; 1: 78.

43. World Health Organisation. Guideline: protecting, promoting and supporting breastfeeding in facilities providing maternity and newborn services. Geneva, Switzerland 2017.

44. Academy of Breastfeeding Medicine Protocol Committee. ABM clinical protocol \#22: guidelines for management of jaundice in the breastfeeding infant equal to or greater than 35 weeks' gestation. Breastfeed Med 2010; 5: 87-93.

45. Committee on Obstetric Practice. Committee Opinion No. 684: Delayed Umbilical Cord Clamping After Birth. Obstet Gynecol 2017; 129: e5-e10.

46. McDonald SJ, Middleton P, Dowswell T, Morris PS. Effect of timing of umbilical cord clamping of term infants on maternal and neonatal outcomes. Evid Based Child Health 2014; 9: 303-97. 
47. Frank R, Garfinkle J, Oskoui M, Shevell MI. Clinical profile of children with cerebral palsy born term compared with late- and post-term: a retrospective cohort study. BJOG 2017; 124:1738-45.

48. Monbaliu E, Himmelmann K, Lin JP, Ortibus E, Bonouvrié L, Feys H, Vermeulen RJ, Dan B. Clinical presentation and management of dyskinetic cerebral palsy. Lancet Neurol 2017; 16: 741-9.

49. Wu YW, Kuzniewicz MW, Wickremasinghe AC, et al. Risk for cerebral palsy in infants with total serum bilirubin levels at or above the exchange transfusion threshold: a population-based study. JAMA Pediatr 2015; 169: 239-46.

50. Shapiro SM, Popelka GR. Auditory impairment in infants at risk for bilirubin-induced neurologic dysfunction. Semin Perinatol 2011; 35: 162-70.

51. Wickremasinghe AC, Risley RJ, Kuzniewicz MW, et al. Risk of Sensorineural Hearing Loss and Bilirubin Exchange Transfusion Thresholds. Pediatrics 2015; 136: 505-12.

52. Akinpelu OV, Waissbluth S, Daniel SJ. Auditory risk of hyperbilirubinemia in term newborns: a systematic review. Int J Pediatr Otorhinolaryngol 2013; 77: 898-905.

53. Amin SB, Saluja S, Saili A, et al. Chronic Auditory Toxicity in Late Preterm and Term Infants with Significant Hyperbilirubinemia. Pediatrics 2017; 140: e20164009.

54. Hua J, Gu G, Jiang P, Zhang L, Zhu L, Meng W. The prenatal, perinatal and neonatal risk factors for children's developmental coordination disorder: a population study in mainland China. Res Dev Disabil 2014; 35: 619-25.

55. Maimburg RD, Olsen J, Sun Y. Neonatal hyperbilirubinemia and the risk of febrile seizures and childhood epilepsy. Epilepsy Res 2016; 124: 67-72.

56. Maimburg RD, Bech BH, Vaeth M, Møller-Madsen B, Olsen J. Neonatal jaundice, autism, and other disorders of psychological development. Pediatrics 2010; 126: 872-8.

57. Amin SB, Smith T, Wang H. Is neonatal jaundice associated with autism spectrum disorders: a systematic review. J Autism Dev Disord 2011; 41: 1455-63.

58. Lozada LE, Nylund CM, Gorman GH, Hisle-Gorman E, Erdie-Lalena CR, Kuehn D. Association of Autism Spectrum Disorders with Neonatal Hyperbilirubinemia. Glob Pediatr Health 2015; 2: 2333794X15596518.

59. Wu YW, Kuzniewicz MW, Croen L, Walsh EM, McCulloch CE, Newman TB. Risk of Autism Associated with Hyperbilirubinemia and Phototherapy. Pediatrics 2016; 138: e20161813.

60. Ku MS, Sun HL, Sheu JN, et al. Neonatal jaundice is a risk factor for childhood asthma: a retrospective cohort study. Pediatr Allergy Immunol 2012; 23: 623-8. 
61. Huang L, Bao Y, Xu Z, Lei X, Chen Y, Zhang Y, Zhang J. Neonatal bilirubin levels and childhood asthma in the US Collaborative Perinatal Project, 1959-1965. Am J Epidemiol 2013; 178: 1691-7.

62. Kuzniewicz MW, Wickremasinghe AC, Newman TB. Invited commentary: does neonatal hyperbilirubinemia cause asthma? Am J Epidemiol 2013; 178: 1698-701.

63. Hokkanen L, Launes J, Michelsson K. Adult neurobehavioral outcome of hyperbilirubinemia in full term neonates: a 30-year prospective follow-up study. Peer J 2014; 2: e294.

64. Maisels MJ, Pathak A, Nelson NM, Nathan DG, Smith CA. Endogenous production of carbon monoxide in normal and erythroblastotic newborn infants. J Clin Invest 1971; 50: 1-8.

65. Jones EA, Shrager R, Bloomer JR, Berk PD, Howe RB, Berlin NI. Quantitative studies of the delivery of hepatic-synthesized bilirubin to plasma utilizing -aminolevulinic acid-4- $14 \mathrm{C}$ and bilirubin- $3 \mathrm{H}$ in man. J Clin Invest 1972; 51: 2450-8.

66. Pearson HA. Life-span of the fetal red blood cell. J Pediatr 1967; 70: 166-71.

67. Blumenthal SG, Stucker T, Rasmussen RD, et al. Changes in bilirubins in human prenatal development. Biochem J. 1980; 186: 693-700.

68. Fevery J, Van de Vijver M, Michiels R, Heirwegh KP. Comparison in different species of biliary bilirubin-IX alpha conjugates with the activities of hepatic and renal bilirubin-IX alphauridine diphosphate glycosyltransferases. Biochem J 1977; 164: 737-46.

69. Bratlid D, Nakstad B, Hansen TW. National guidelines for treatment of jaundice in the newborn. Acta Paediatr. 2011; 100: 499-505.

70. Maisels MJ, Watchko JF, Bhutani VK, Stevenson DK. An approach to the management of hyperbilirubinemia in the preterm infant less than 35 weeks of gestation. J Perinatol 2012; 32: 660-4.

71. van Imhoff DE, Dijk PH, Hulzebos CV; BARTrial study group, Netherlands Neonatal Research Network. Uniform treatment thresholds for hyperbilirubinemia in preterm infants: background and synopsis of a national guideline. Early Hum Dev 2011; 87: 521-5.

72. Kaplan M, Hammerman C, Bhutani VK. Parental education and the WHO neonatal G-6-PD screening program: a quarter century later. J Perinatol 2015; 35: 779-84.

73. Wennberg RP, Watchko JF, Shapiro SM. Maternal Empowerment - An Underutilized Strategy to Prevent Kernicterus? Curr Pediatr Rev 2017; 13: 210-9.

74. Luu MN, Le LT, Tran BH, et al. Home-use icterometry in neonatal hyperbilirubinaemia: Cluster-randomised controlled trial in Vietnam. J Paediatr Child Health 2014; 50: 674-9.

75. Xue GC, Ren MX, Shen LN, Zhang LW. Parental infant jaundice colour card design successfully validated by comparing it with total serum bilirubin. Acta Paediatr 2016; 105 : e561-6. 
76. Olusanya BO, Slusher TM, Imosemi DO, Emokpae AA. Maternal detection of neonatal jaundice during birth hospitalization using a novel two-color icterometer. PLoS One 2017; 12 : e0183882.

77. US Preventive Services Task Force. Screening of infants for hyperbilirubinemia to prevent chronic bilirubin encephalopathy: recommendation statement. Pediatrics 2009; 124: 1172-7.

78. Bhardwaj K, Locke T, Biringer A, et al. Newborn Bilirubin Screening for Preventing Severe Hyperbilirubinemia and Bilirubin Encephalopathy: A Rapid Review. Curr Pediatr Rev 2017; 13: 67-90.

79. Ahlfors CE. Predicting bilirubin neurotoxicity in jaundiced newborns. Curr Opin Pediatr 2010; 22: $129-33$.

80. Amin SB, Lamola AA. Newborn jaundice technologies: unbound bilirubin and bilirubin binding capacity in neonates. Semin Perinatol 2011; 35: 134-40.

81. Watchko JF. Measurement of Circulating Unbound Bilirubin: Will It Ever Be a Part of Routine Neonatal Care? J Pediatr 2016; 173: 6-7.

82. Hulzebos CV, Dijk PH. Bilirubin-albumin binding, bilirubin/albumin ratios, and free bilirubin levels: where do we stand? Semin Perinatol 2014; 38: 412-21.

83. Iskander I, Gamaleldin R, El Houchi S, et al. Serum bilirubin and bilirubin/albumin ratio as predictors of bilirubin encephalopathy. Pediatrics 2014; 134: e1330-9.

84. Kirk JM. Neonatal jaundice: a critical review of the role and practice of bilirubin analysis. Ann Clin Biochem 2008; 45: 452-62.

85. Kazmierczak SC, Robertson AF, Catrou PG, Briley KP, Kreamer BL, Gourley GR. Direct spectrophotometric method for measurement of bilirubin in newborns: comparison with HPLC and an automated diazo method. Clin Chem 2002; 48: 1096-7.

86. Engle WD, Jackson GL, Engle NG. Transcutaneous bilirubinometry. Semin Perinatol. 2014; 38 : 438-51.

87. Taylor JA, Burgos AE, Flaherman V, et al. Discrepancies between transcutaneous and serum bilirubin measurements. Pediatrics 2015; 135: 224-31.

88. Olusanya BO, Imosemi DO, Emokpae AA. Differences Between Transcutaneous and Serum Bilirubin Measurements in Black African Neonates. Pediatrics 2016; 138: e20160907.

89. Greco C, Iskander IF, Akmal DM, et al. Comparison between Bilistick System and transcutaneous bilirubin in assessing total bilirubin serum concentration in jaundiced newborns. J Perinatol 2017; 37: 1028-31.

90. Letamendia-Richard E, Ammar RB, Tridente A, De Luca D. Relationship between transcutaneous bilirubin and circulating unbound bilirubin in jaundiced neonates. Early Hum Dev 2016; 103: 235-9. 
91. Nagar G, Vandermeer B, Campbell S, Kumar M: Effect of Phototherapy on the Reliability of Transcutaneous Bilirubin Devices in Term and Near-Term Infants: A Systematic Review and Meta-Analysis. Neonatology 2016; 109: 203-12.

92. Hassan Shabuj M, Hossain J, Dey S. Accuracy of transcutaneous bilirubinometry in the preterm infants: a comprehensive meta-analysis. J Matern Fetal Neonatal Med 2017 Oct 26:1-8. [Epub ahead of print]

93. Keahey PA, Simeral ML, Schroder KJ, et al. Point-of-care device to diagnose and monitor neonatal jaundice in low-resource settings. Proc Natl Acad Sci USA 2017; 114: E10965E10971.

94. Taylor JA, Stout JW, de Greef L, et al. Use of a Smartphone App to Assess Neonatal Jaundice. Pediatrics 2017; 140: e20170312.

95. Bhutani VK, Kaplan M, Glader B, Cotten M, Kleinert J, Pamula V. Point-of-Care Quantitative Measure of Glucose-6-Phosphate Dehydrogenase Enzyme Deficiency. Pediatrics 2015; 136: e1268-75.

96. Xiong T, Qu Y, Cambier S, Mu D. The side effects of phototherapy for neonatal jaundice: what do we know? What should we do? Eur J Pediatr 2011; 170: 1247-55.

97. Ebbesen F, Hansen TWR, Maisels MJ. Update on Phototherapy in Jaundiced Neonates. Curr Pediatr Rev 2017; 13: 176-80.

98. Woodgate P, Jardine LA. Neonatal jaundice: phototherapy. BMJ Clin Evid 2015; 2015: 0319.

99. Slusher TM, Olusanya BO, Vreman HJ, et al. A Randomized Trial of Filtered Sunlight Phototherapy in African Neonates. New Engl J Med 2015; 373:1115-24.

100.Gholitabar M, McGuire H, Rennie J, Manning D, Lai R. Clofibrate in combination with phototherapy for unconjugated neonatal hyperbilirubinaemia. Cochrane Database Syst Rev 2012; 12: CD009017.

101.Lai NM, Ahmad Kamar A, Choo YM, Kong JY, Ngim CF. Fluid supplementation for neonatal unconjugated hyperbilirubinaemia. Cochrane Database Syst Rev 2017; 8: CD011891.

102. Huizing KMN, Røislien J, Hansen TWR. Intravenous immune globulin significantly reduces the need for exchange transfusions in infants with Rhesus and ABO incompatibility. Acta Paediatr 2008; 97: 1362-5.

103. Murki S, Kumar P. Blood exchange transfusion for infants with severe neonatal hyperbilirubinemia. Semin Perinatol 2011; 35: 175-84.

104. Mabogunje CA, Emokpae AA, Olusanya BO. Predictors of Repeat Exchange Transfusion for Severe Neonatal Hyperbilirubinemia. Pediatr Crit Care Med 2016; 17: 231-5.

105. Schulz S, Wong RJ, Vreman HJ, Stevenson DK. Metalloporphyrins - an update. Front Pharmacol 2012; 3: 68. 
106.Kaplan M, Kaplan E, Hammerman C, et al. Post-phototherapy neonatal bilirubin rebound: a potential cause of significant hyperbilirubinaemia. Arch Dis Child 2006; 91: 31-4.

107.Hansen TW, Nietsch L, Norman E, et al. Reversibility of acute intermediate phase bilirubin encephalopathy. Acta Paediatr 2009; 98: 1689-94.

108.Hansen TW. Prevention of neurodevelopmental sequelae of jaundice in the newborn. Dev Med Child Neurol 2011; 53 Suppl 4: 24-8.

109.Olusanya BO. State of the world's children: life beyond survival. Arch Dis Child 2005; 90: 317-8.

110.World Health Organisation. Nurturing Care Framework for Early Child Development.

[Available at: http://www.who.int/maternal_child_adolescent/child/nurturing-careframework/en/. Accessed. 25 March 2018].

111.Cremer RJ, Perryman PW, Richards DH. Influence of light on the hyperbilirubinemia of infants. Lancet 1958; 1: 1094-7.

112.Mollison PL, Cutbush M. Exchange transfusion in haemolytic disease of the newborn. Lancet 1948; 2: 522-7.

113.Day RL. Kernicterus problem: Experimental in vivo and in vitro staining of brain tissue with bilirubin. Am J Dis Child 1947; 73: 241-2.

114.Bellarosa C, Bortolussi G, Tiribelli C. The role of ABC transporters in protecting cells from bilirubin toxicity. Curr Pharm Des 2009; 15: 2884-92.

115.Brites D. The evolving landscape of neurotoxicity by unconjugated bilirubin: role of glial cells and inflammation. Front Pharmacol 2012; 3: 88.

116.Riordan SM, Bittel DC, Le Pichon JB, et al. A Hypothesis for Using Pathway Genetic Load Analysis for Understanding Complex Outcomes in Bilirubin Encephalopathy. Front Neurosci 2016; $10: 376$.

\section{Legends}

1. Panel. Categories of clinically significant hyperbilirubinaemia

2. Table 1. Risk factors for severe hyperbilirubinaemia

3. Table 2. Management of neonatal hyperbilirubinaemia

4. Figure 1. Haem synthesis, degradation and excretion 
Significant hyperbilirubinaemia

Unconjugated bilirubin level requiring treatment with phototherapy which varies with postnatal age and aetiology (typically TSB $\geq 12 \mathrm{mg} / \mathrm{dL}$ or $205 \mu \mathrm{mol} / \mathrm{L}$ ).

Severe hyperbilirubinaemia

Bilirubin levels at/near exchange transfusion levels based on post-natal age and aetiology (typically TSB $\geq 20 \mathrm{mg} / \mathrm{dL}$ or $342 \mu \mathrm{mol} / \mathrm{L}$ ) and/or any elevated TSB associated with early signs of mild acute bilirubin encephalopathy (ABE).

\section{Extreme hyperbilirubinaemia}

Bilirubin levels at exchange transfusion levels (typically TSB $\geq 25 \mathrm{mg} / \mathrm{dL}$ or $428 \mu \mathrm{mol} / \mathrm{L}$ ) and/or any elevated TSB associated with signs of mild to moderate ABE.

\section{Hazardous or critical hyperbilirubinaemia}

Bilirubin levels at exchange transfusion levels (typically TSB $\geq 30 \mathrm{mg} / \mathrm{dL}$ or $513 \mu \mathrm{mol} / \mathrm{L}$ ) and/or any elevated TSB associated with signs of moderate to severe ABE.

\section{Bilirubin encephalopathy}

Abnormal neurological signs and symptoms caused by bilirubin toxicity to the basal ganglia and various brainstem nuclei. It progresses from an acute phase to the chronic form as kernicterus.

Acute bilirubin encephalopathy (ABE)

Acute manifestations of bilirubin toxicity seen within fourteen days after birth. Signs and symptoms of $\mathrm{ABE}$ are typically classified as mild (poor feeding, lethargy and tone abnormalities), moderate/intermediate (high-pitched cry, irritability and increasing hypertonia), or severe/advanced (deep stupor, fever, apnoea, inability to feed, retrocollis, opisthotonos, and obtundation).

\section{Chronic bilirubin encephalopathy (or Kernicterus)}

Permanent or chronic neurologic damage, including choreo-athetoid cerebral palsy, enamel dysplasia, paralysis of upward gaze, hearing impairments including auditory neuropathy spectrum disorders.

Table 1. Risk factors for severe neonatal hyperbilirubinaemia

\section{Genetic factors}

- Gilbert's syndrome

- Crigler-Najjar syndrome

- Alagille's syndrome

- Beta thalassemia

- Glucose-6-phosphate dehydrogenase deficiency

- Bilirubin glucuronosyltransferase polymorphism

- Pyruvate kinase deficiency

- Erythrocyte structural defects (including Hereditary Spherocytosis and Elliptocytosis)

- Galactosaemia

\section{Maternal factors}




\section{Table 2. Management of neonatal hyperbilirubinaemia}

- Race or ethnic group

- Family history of severe jaundice

- Primiparity

- Teenage pregnancy

- Diabetes mellitus

- Rh incompatibility

- ABO incompatibility

- Drugs during labour (including oxytocin, promethazine and bupicaine)

- Exclusive breast-feeding

\section{Perinatal factors}

- Mode of delivery (breech vs vertex, instrumentation)

- Birth trauma (Cephalohematoma or significant bruising, extravasation)

- Birth asphyxia

- Delayed cord clamping

- Congenital infections (including cytomegalovirus and syphilis)

- Sepsis

\section{Neonatal factors}

- Male gender

- Prematurity/Low birth weight and small-for-gestational age

- Hypothyroidism

- Polycythaemia

- Hypoglycaemia

- Low intake of breast milk and/or Dehydration, weight loss

- Breast milk jaundice

\section{Other risk factors/markers}

- Previous sibling received phototherapy/EBT

- Pre-discharge TSB or TcB level in the high-risk zone

- Use of haemolytic agents (Naphthalene/menthol-based products, etc) in G6PD deficient population groups

- Folate deficiency

- Aflatoxins

- Hypothermia

- Out-born/non-institutionalised birth

TcB: transcutaneous bilirubin, TSB: total plasma/serum bilirubin [Adapted from: Dennery et al, NEJM 2001 (ref 2) \& Olusanya et al, PLoS One. 2015 (ref 34)]. 


\section{Primary prevention}

- Education of existing and expectant mothers, families and health care providers on

- The transient physiologic course but with potential to increase to harmful levels and its variability from baby to baby

- The avoidance of haemolytic substances (including camphor/naphthalene balls, menthol-containing powder, creams, balms and Eucalyptus oil).

- The benefits of early detection accompanied by timely and appropriate treatment in health facilities adequately-equipped for newborn care.

- Discouraging traditional therapies as well as indiscriminate use of self-prescribed medications e.g. ampicillin-cloxacillin.

- Recognition of acute bilirubin encephalopathy (ABE)/Bilirubin-Induced Neurologic Dysfunction (BIND)

- The value of "clean birth" to prevent or minimise the risk of infection (sepsis)

- Referral to secondary or tertiary centres of all preterm babies ( $<35$ weeks gestation) and surveillance for fullterm infants with history of medically-treated jaundice in a sibling presenting at primary health centres.

- Promotion and support for successful breastfeeding.

- Screening of expectant mothers for the risk of blood group incompatibilities using routine ABO \& Rh with counselling on the importance of $\mathrm{Rh}$ immunoglobulin ensuring availability when indicated.

- Judicious use of oxytocin during labour.

- Identification of babies with extensive bruises, cephalohematomas, fractures and at risk for concealed hematomas e.g. those from difficult deliveries.

- Request blood test to rule out Glucose-6-phosphate dehydrogenase (G6PD) deficiency in high-risk populations.

- Early phototherapy for infants with haemolytic diseases.

\section{Early detection, diagnosis and monitoring}

- Routine examination of all newborns within 24 hours of birth and the next 48 hours for possible jaundice.

- Monitoring of infants who had delayed cord clamping at birth.

- If jaundice is suspected, examine infant naked in a well-lit room or, preferably in natural daylight near a window guided by Kramer's chart. Recognise that estimation of the degree of hyperbilirubinaemia based on visual signs of jaundice can lead to errors, particularly in darkly pigmented infants. Blanching of the gum may be more reliable and helpful in dark skinned babies.

- If jaundice is visible, measure the total serum bilirubin (TSB) or transcutaneous bilirubin (TcB) level. TcB values above $12 \mathrm{mg} / \mathrm{dl}(205 \mu \mathrm{mol} / \mathrm{L})$ should be cross-checked where possible with TSB measurement.

- Establish if infant has early signs of $\mathrm{ABE}$ or qualifies as high risk including possible haemolytic diseases, hypothermia, hypoglycaemia, or sepsis.

- Refer to actionable levels for measured TSB or TCB in a relevant clinical guideline for the population.

- Ensure follow-up of infants discharged before 48 hours after delivery especially those with established risk factors within 1-2 days of discharge (take advantage of the earliest routine immunisation visit and any other times infants $<2$ weeks are seen).

\section{Treatment}

- Refer to recommended age-specific actionable levels for the population.

- When indicated (particularly, in the presence of isoimmune haemolytic diseases), ensure early treatment of newborns with intensive phototherapy to minimise the need for exchange transfusion.

- Ensure that the irradiance levels of phototherapy units are periodically monitored, and the recommended specifications strictly followed.

- Be familiar with simple and inexpensive adjustments that can significantly improve the effectiveness of phototherapy devices.

- Maximise irradiance by placing the units as close as possible without overheating the infants (usually $10-20 \mathrm{~cm}$ above the baby if using cool lights (unless specified otherwise by manufacturer), using white reflecting materials on all sides of cots, exposing as much of the baby as possible (thereby maximising spectral power [irradiance $\mathrm{x}$ size of irradiated area]); and change florescent tubes according to manufacturer's recommendations if available or periodically (8-12 weeks) if unable to measure irradiance levels. Where special blue tubes are not available, use ordinary daylight fluorescent tubes. 
- Ensure that the eyes are covered but keep the cover small to maximise skin surface available for phototherapy.

- Ensure that male genitals are covered (controversial) unless for infants nearing exchange transfusion level.

- Ensure that babies are placed in cots not incubators when under phototherapy unless they are hypothermic.

- Ensure that blood samples for relevant investigations are collected and refrigerated before initiating exchange transfusion and any blood samples are protected from light including the phototherapy light. In infants admitted with extreme jaundice and/or signs of ABE, DO NOT DELAY START OF PHOTOTHERAPY while waiting for lab specimens to be drawn.

- Ensure that an infant with clinical signs of moderate-severe ABE receives exchange transfusion promptly. Place the infant under the best phototherapy available while preparing for the exchange transfusion. While waiting for blood to be prepared for an exchange, IVIG $(0.5-1 \mathrm{G} / \mathrm{kg})$ may help to stem the rise in TSB, especially in $\mathrm{ABO}$ hetero-specific newborns. It may need to be repeated after the exchange.

- Ensure that the infant remains adequately hydrated and is breastfeeding well/feeding well.

- Avoid drugs that compete for albumin binding such as sulfonamides, ceftriaxone, and acetylsalicylic acid.

- Ascertain the risk of bilirubin rebound after phototherapy and/or exchange transfusion before hospital discharge.

\section{Follow-up evaluation}

- Assess non-jaundiced infants on days 3 and 5.

- Assess jaundiced infants regularly in the first 7-10 days or until jaundice is clearly resolved, even after receiving treatment.

- Educate parents on the need for a follow-up neuro-developmental assessment of all infants treated for severe hyperbilirubinaemia with intensive phototherapy or exchange transfusion or with a history of such treatment at age 3-6 months.

- Ensure that, at the minimum, such developmental assessment includes auditory brainstem response audiometry, language processing/language development and clinical evaluation of abnormalities of tone, posture and movements for infants with signs of ABE/BIND, who had exchange transfusion and those with a bilirubin level of $\geq 20 \mathrm{mg} / \mathrm{dL}$.

- Disseminate information on the local providers of age-appropriate developmental evaluation of infants and young children to the affected parents on discharge or during any subsequent clinical consultations.

Adapted from: AAP Guidelines, Pediatrics 2004 [ref 33], NICE 2010 [ref 14] \& Olusanya et al. BMC Pediatr 2015 [ref 19] 
$\rightarrow$ Haem <-- Haemoproteins (Peroxidase, cytochromes \& myoglobin) Production

\section{Haem oxygenase}

Biliverdin reductase

$\longrightarrow 3[\mathrm{O}]$

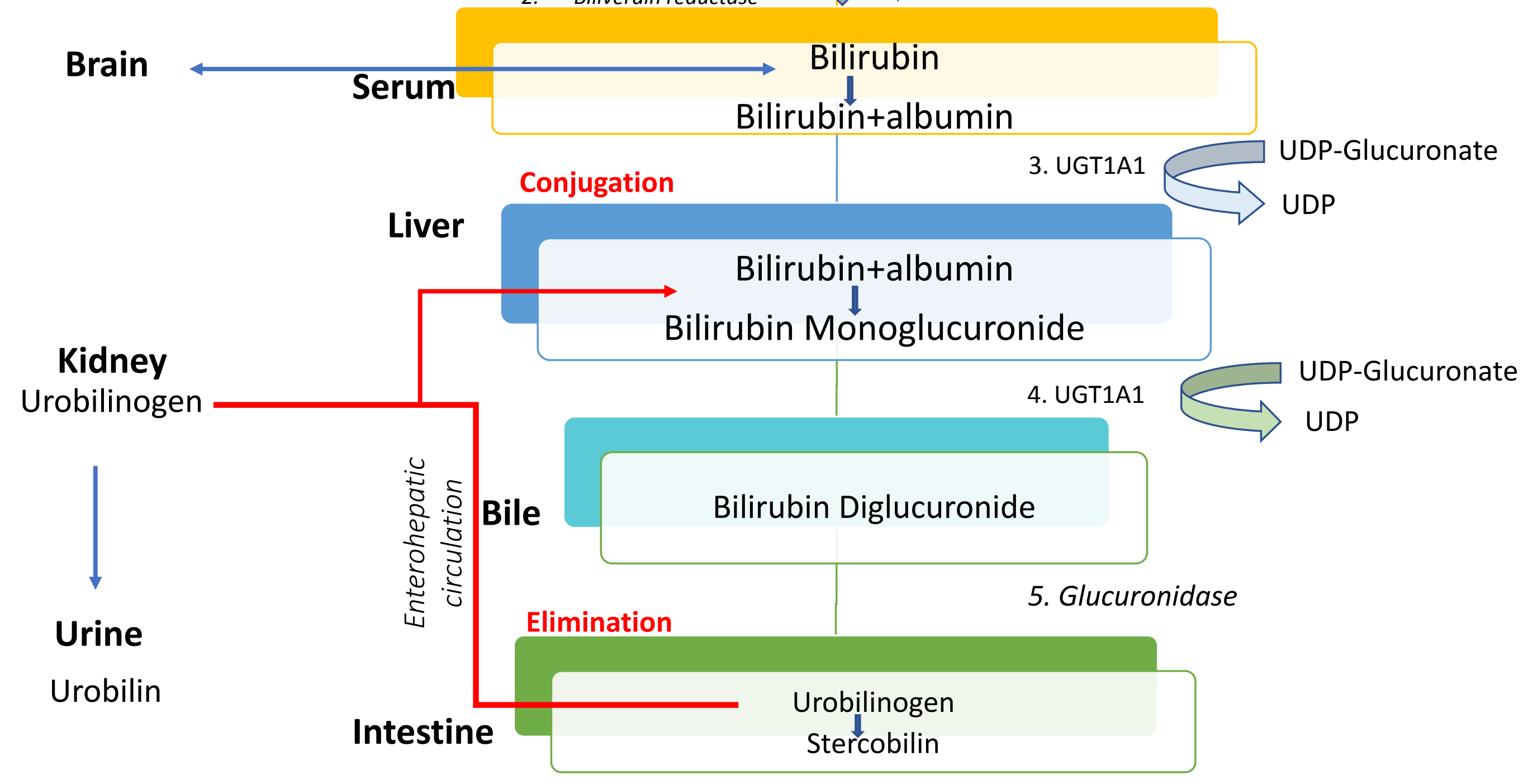


Manuscript: THELANCETCHILDADOL-D-18-00142

Title: Neonatal hyperbilirubinaemia

\section{Response to Reviewers' comments}

\section{Reviewer \#1:}

1. Is there any evidence to support infant massage in preventing or reducing hyperbilirubinaemia in newborns? Reply: The evidence in the literature is mixed. In fact, only few studies with small sample sizes have demonstrated that infant massage reduces bilirubin levels and increases the frequency of defecation in infants receiving phototherapy. However, the effects have not yet been demonstrated in infants with severe hyperbilirubinaemia. As a result, infant massage cannot be recommended as a replacement for established treatments.

2. Is there any evidence to suggest that bilirubin protects against ROP in premature neonates?

Reply: Bilirubin is known to be an effective antioxidant. However, the evidence that it protects against ROP in premature infants is inconclusive. Thus, while a few studies report a protective effect (Heyman E et al 1989, Yeo KL et al 1998), the majority of published studies find no such evidence (Boynton BR and Boynton CA 1989, Gaton DD et al 1991, Fauchere JC et al 1994, Hosono S et al 2002, Dejonge MH et al 1999, Milner JD et al 2003).

3. How were the levels of bilirubin for moderate, severe and critical hyperbilirubinaemia arrived at? Is there follow up of infants with 'near-to-severe' levels of bilirubin levels?

Reply: These levels are simply based on experts' opinion. They are more useful as qualitative descriptors of bilirubin levels rather than stand-alone criteria for initiating treatment.

4. Is there a linear increase in neurological risk? And if not why not?

Reply: Strictly speaking, no. Although the neurological risk clearly rises with TSB levels, there is no linearity. While some babies develop kernicterus at $20 \mathrm{mg} / \mathrm{dL}$, others have tolerated much higher levels (3035-40) without damage. It is clear that bilirubin toxicity is modulated by a number of factors, some of which we know about (haemolysis, respiratory acidosis, sepsis, increased blood-brain barrier permeability, asphyxia, to mention but a few), and others about which we are only guessing or speculating (such as bilirubin oxidation in brain, or "flippases" in the blood-brain barrier).

5. Any suggestions for rebound hyperbilirubinaemia after phototherapy?

Reply: This observation is appreciated and has been reflected in the main text [see page 15, para 3]. It is also added to the sections on treatment $\&$ follow-up under Table 2 .

6. Until there is a safe, simple, reliable point of care test for use in Health Centres across Africa what advice would you give concerning the clinical assessment of levels of jaundice. What tool is the easiest and best of all the clinical tools? Who should use it?

Reply: We are not aware of any tools that satisfy these criteria completely without some downsides. Perhaps the easiest and cheapest add-on to visual inspection may be the Gossett/Ingram colour strip. Visual inspection is, sadly, a poor discriminator. Given the fact that cell phones seem to be quite widely distributed smartphone apps do carry some promise. Clinical assessment of the risk of ABE using a BIND scoring system may also be helpful. However, these tools are not fool-proof against low bilirubin kernicterus.

\section{Reviewer \#2:}

7. The section on pathophysiology of bilirubin (page 9-10) is unnecessary and does not fit in the philosophy of the review. Several recent and less recent review papers addressed the issue compressively. I suggest remove this section.

Reply: This section is a standard requirement for seminar papers in the Lancet journals.

8. The limitation of measuring accurately TSB above $16-18 \mathrm{mg} / \mathrm{dL}$ with TcB must be mentioned. The comparison with the POC bilistick (ref 92) should be expanded.

Reply: We have provided additional information on TcB as suggested [page 13, para 1]. However, we have refrained from discussing any particular brand of POC equipment such as Bilistick for ethical reasons. 


\section{Editorial comments:}

1. Please add a conflict of interest statement that matches the declarations on your ICMJE forms that were submitted earlier. Authors should be referred to by their initials in this section. If there are none, then please state "The authors declared no conflicts of interest" or "The other authors declared no conflicts of interest".

Reply: Done. See section before references

2. As well as the ICMJE form, all authors need to sign this form: http://www.thelancet.com/pb/assets/raw/Lancet/authors/tlchild-author-signatures.pdf

Reply: Done.

3. Please add a contributors' section, detailing specifically what each author did in the preparation of this manuscript. These statements should match those in your author statement form.

Reply: Done. See section before references

4. We require confirmation that the paper has not been submitted to another journal and has not been published in whole or in part elsewhere previously.

Reply: Confirmation provided in the cover letter.

5. For papers listed in references that are "in press" we need to see a galley proof and letter from the publisher stating that it is 'in press' as well as the full expected citation (i.e., publication date/volumel issue etc).

Reply: Not applicable.

6. Please check with your co-authors, and confirm, that all names are spelt correctly, and affiliations listed correctly. We cannot guarantee that we will be able to correct names and affiliations after publication of your article.

Reply: Done.

7. Please provide: one preferred degree qualification per author and indicate any full professors; affiliation details (department, institute, city, state, country) for each author; full institutional correspondence address for corresponding author.

Reply: Done.

8. References should be in the Vancouver style and numbered in the order in which they first appear in the manuscript. If the references "move" from the body text into tables or figures, please maintain the sequence of citation. Please ensure tables and figures are cited correctly in the body text to prevent the need for renumbering of references should the table and figure citations subsequently move.

Reply: Done.

9. Please ensure that reference numbering throughout the manuscript is not inserted with electronic referencing software, such as Endnote.

Reply: Done.

10. Please state whether this study was fully or in part NIH funded, if any authors are employed by NIH, or if any authors are receipt of an NIH grant.

Reply: No funding was received by any of the authors for this work. 